\title{
Adição de Rugosidade ao Concreto de Escadas para Peixes: Análise para a Espécie Neotropical Pimelodus Maculatus
}

\author{
Isabella Cristina Resende Ramos, Luiz Gustavo Soyer Freire,Guilherme Gonçalves Soares, \\ Isadora Carvalho da Silva, Pedro Henrique Viana de Araujo Lopes, Nathália Couto Machado, \\ Hersília de Andrade e Santos \\ hsantos@civil.cefetmg.br
}

Recebido: 01/02/12 - revisado: 30/07/12 - aceito: 22/07/14

\section{RESUMO}

O Brasil possui um dos maiores parques hidrelétrico do mundo. Este potencial de aproveitamento apresenta um conjunto de condicionantes. Destaque para implicações de ordem ambiental como a interrupção da migração de algumas espécies de peixes, cujos sítios de desova se localizam a montante dos barramentos. Para solucionar este problema ambiental foram desenvolvidos os mecanismos de transposição de peixes (MTP). A escada do tipo ranhura vertical é um MTP normalmente construída em concreto liso, o que torna seu ambiente interno completamente diferente do leito natural dos rios. Este trabalho teve como objetivo avaliar o efeito do aumento da rugosidade nas ranhuras de uma escada sobre o escoamento hidráulico, analisando também a influência deste escoamento no comportamento de uma espécie de peixe neotropical, Pimelodus maculatus. Para isto foi construído um modelo reduzido em laboratório e testados exemplares de peixes no período noturno. Os resultados demonstram que há uma preferência da espécie por paredes rugosas para a vazão cujo escoamento apresenta valores de tensão turbulenta no plano xy da ordem máxima de 35 Pa. Os parâmetros hidráulicos velocidade pontual e tensão turbulenta no plano xy apresentaram maior alteração em função da adoção da rugosidade para diferentes valores de vazão dentro da escada.

Palavras-chave: escada ranhura vertical, rugosidade e Pimelodus maculatus.

\section{INTRODUÇÃO}

O Brasil conta com um dos maiores parques hidrelétrico de todo o mundo. Além de tratar de uma fonte abundante, a alternativa hidrelétrica constitui hoje uma área de pleno domínio pela tecnologia nacional. Essa característica da matriz energética brasileira apresenta, porém, um conjunto de condicionantes para o setor elétrico brasileiro.

Destacam-se as implicações de ordem ambiental, associadas aos impactos das usinas hidrelétricas. As interrupções causam danos à biota local, afetando diretamente as espécies migradoras, que necessitam deslocar-se ao longo do rio em alguma fase de seu ciclo de vida, provocando fragmentação dos rios e mudanças das características lóticas para lênticas. (SANTOS et al., 2009; VIANA et al., 2009; PELICICE e AGOSTINHO, 2008; KUAMAL e FERREIRAL, 2009). Para solucionar esse

Departamento de Engenharia Civil - Centro Federal de Educação Tecnológica de Minas Gerais (CEFET-MG) problema ambiental foram desenvolvidas estruturas que permitem ao peixe a transposição desses obstáculos. Conhecidas como mecanismos de transposição de peixes (MTP), tais estruturas passaram a ser amplamente utilizadas em todo do mundo (SANTOS, et al., 2009).

As diferentes condições encontradas nos barramentos, relativas aos desníveis e à disponibilidade de espaço para construção desses mecanismos, levaram ao desenvolvimento de vários tipos de MTP para montante. Esses diversos dispositivos são classificados em escadas, canais para transposição, eclusas ou elevadores de peixes (LARINIER, 2002).

Uma das escadas que vem sendo empregadas no Brasil é a do tipo ranhura vertical e consiste em canais nos quais os diferentes tipos de anteparos criam tanques, aonde é possível o peixe descansar (SANTOS et al., 2009).

As escadas, na maioria das vezes, são construídas em concreto liso representando um ambiente completamente diferente dos ambientes encontrados normalmente no leito dos rios. 
Segundo Martins (2005), nos empreendimentos com pequenos desníveis são comuns, principalmente na Europa, os MTP's tipo "like a river" ou "nature like fishways". Estes consistem em canais artificiais para a passagem de peixes que simulam um rio natural. Os canais semi-naturais atendem a requisitos de ordem biológica de forma mais satisfatória do que estruturas tais como escadas, elevadores ou eclusas (JUNHO, 2008).

Muitos são os tipos e detalhes dos mecanismos de transposição de peixes (MTP's). Eles são construídos em função das características locais, dos cardumes e das condições de contorno do local, tais como desnível a ser vencido, inclinação do canal, capacidade natatória das espécies a serem transpostas. Desta forma um MTP pode ser seletivo caso não considere estas características. De acordo com Pompeu e Martinez (2007), a seletividade refere-se à seleção de diferentes espécies ou classes de tamanho.

A seletividade destas estruturas tem sido negligenciada no Brasil quando estas são avaliadas para fins de conservação da fauna de peixes neotropicais (AGOSTINHO et al., 2002). Como possíveis causas desta seletividade tem-se a não adequação das características hidrodinâmicas, tais como a velocidade da água e alta turbulência (MAKRAKIS et al., 2007) as demandas biológicas ; a falta de estudo das espécies da região e a ausência do trabalho em conjunto dos engenheiros com biólogos.

A criação de ambientes semelhantes aos encontrados naturalmente em rios é uma alternativa que pode reduzir a seletividade das escadas no Brasil. Este trabalho, portanto, teve como objetivo avaliar o efeito do aumento da rugosidade nas ranhuras verticais sobre o escoamento hidráulico de uma escada, analisando também a influência deste escoamento no comportamento de uma espécie de peixe neotropical, Pimelodus maculatus. Para este estudo foi construído um modelo em escala reduzida da escada de peixe tipo ranhura vertical no laboratório de hidráulica do CEFET-MG.

\section{Escadas para peixes}

Segundo Viana et al.(2009), os dispositivos de transposição podem ser agrupados em: elevadores, eclusas e escadas. A escada do tipo ranhura vertical é um mecanismos de transposição de peixes para montante (FIG. 1) e possui anteparos de diferentes formas inseridas em suas paredes. A abertura entre esses anteparos permite aos peixes a passagem de um tanque para outro. A vantagem do modelo ranhura vertical está na sua capacidade de manipular grandes variações dos níveis d' água (KATOPODIS, 1992).

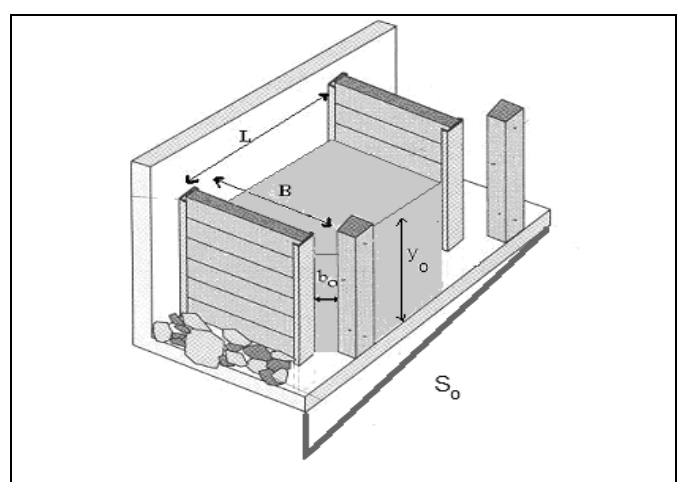

Figura 1- Variáveis hidráulicas das escadas do tipo ranhura vertical. Feita pelos autores.

Para o dimensionamento de uma escada do tipo ranhura vertical (FIG. 1) três parâmetros geométricos são importantes: abertura da ranhura (bo), altura da lâmina d'água (yo) e inclinação da escada (So), sendo os dois primeiros relacionados às características da ictiofauna e o último relacionado às características do obstáculo a ser transposto.

Normalmente, as escadas para peixes no Brasil são construídas em concreto liso. Entretanto, várias experiências internacionais, têm mostrado que canais semi-naturais, os quais buscam similaridade com ambientes naturalmente encontrados em rios, tem se apresentado um boa solução para transposição (BALDIGO et al., 2008). Desta forma, uma alternativa para alterar seletividade das escadas podem estar no tipo de material utilizado na construção destas estruturas.

\section{Concretos utilizados em escadas para peixes}

A composição básica do concreto, utilizado em escadas para peixes, é dada pela mistura de água, agregados (areia, brita entre outros), aditivos e cimento Portland.

Quando são adicionados agregados com propriedades específicas ao concreto, muda-se também as propriedades deste último (MEHTA e MONTEIRO, 2005), como por exemplo a resistência mecânica.

Para alterar as características rugosas do concreto de uma escada para peixes, foi proposta a adição agregados leves. Estes podem ser naturais ou sintéticos e são menos porosos que agregados convencionais (brita). Os agregados leves 
usualmente são resistentes e capazes de produzir concretos estruturais, isolantes e para produção de blocos de alvenaria.

Neste trabalho foram utilizados agregados leves (argila expandida), seixos rolados para alteração da rugosidade das ranhuras verticais, internas ao canal da escada.

\section{MATERIAIS E MÉTODOS}

Para análise dos efeitos da adição de concreto rugoso em escadas para peixes, foi montado um canal com formado por três tanques em laboratório. As ranhuras construídas para criar a piscinas deste canal, foram construídas com adição de agregados especiais. Em seguida foram realizados testes de medição hidráulica e experimentos com a espécie de peixe Pimelodus maculatus.

\section{Construção dos Anteparos}

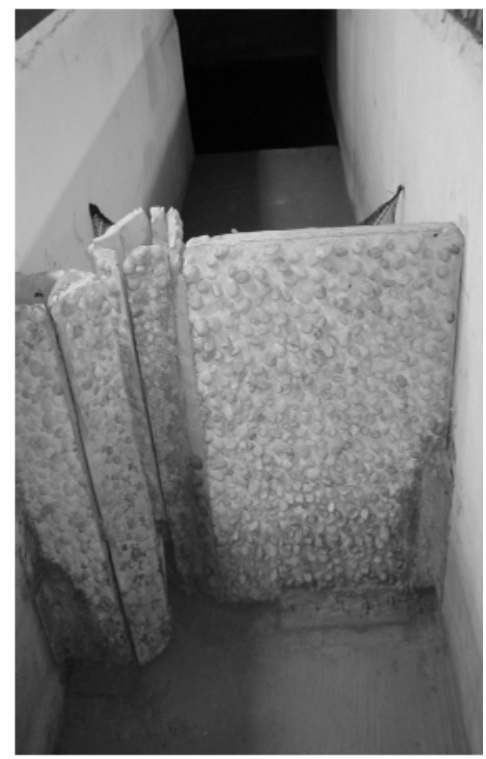

Figura 2- Ranhura no canal de concreto.

As ranhuras, utilizadas nesse trabalho, foram montadas a partir da conexão de várias partes. Estas foram produzidas em fôrmas finas $(1,5 \mathrm{~cm}$ de altura) para que os agregados graúdos ficassem aparentes, deixando, assim, rugosa a textura superficial do concreto. Para a concretagem de uma ranhura completa, foi necessário um volume de 26 litros de concreto, produzidos com $5 \mathrm{Kg}$ de cimento, $10 \mathrm{Kg}$ de areia, 1,53 litros de argila expandida e 2,75 litros de água. As peças foram preparadas para posterior anexação das cantoneiras. Para a fixação das paredes formando as ranhuras, foi utilizado o cimento graute. Parafusos foram colocados nas laterais e fundos das peças enquanto elas estavam em processo de pega. Os parafusos então foram inseridos nos furos executados em cantoneiras, já colocadas no canal hidráulico.

As ranhuras em concreto foram disposta de forma a criar 3 tanques(FIG. 2). A numeração delas seguiu a ordem da entrada da água no canal (FIG. $3)$.

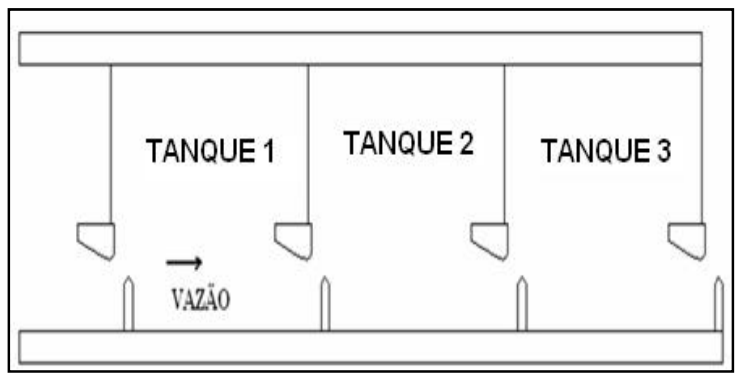

Figura 3 - Vista superior dos tanques do modelo reduzido produzido

No caso do modelo ranhura vertical, adotaram-se os critérios construtivos propostos por Rajaratnam, Van der Vinne e Katopodis (1986). A partir da largura do canal, $86 \mathrm{~cm}$, foi calculada a abertura da ranhura, bo $(11 \mathrm{~cm})$, e o comprimento dos tanques, L $(108 \mathrm{~cm})$.

\section{Medições Hidráulicas}

Para as medições hidráulicas foi utilizado um medidor do tipo ADV (Acoustic Doppler Velocimeter), que através do efeito Doppler, infere a velocidade de partículas presentes na água nas três direções $(x, y$ e $z$ ). O posicionamento da sonda do ADV foi realizado por meio de um sistema de trilhos com um carro móvel sobre o canal hidráulico (FIG. $4)$.

As medidas foram feitas para 3 vazões (15, 20 e $35 \mathrm{l} / \mathrm{s})$. As medições pontuais foram feitas a cada 5 centímetros (nos planos horizontais e verticais). Em cada ponto eram coletadas 100 medidas de velocidade (freqüência de $10 \mathrm{~Hz}$ ).

Após a coleta de dados com o software Horizon da Sontek, os dados foram exportados para o formato txt. Com os valores de velocidade nas três direções, foram calculadas as flutuações da 
velocidade (EQ. 1) e a tensão cisalhante em xy (EQ. 2):

$$
u^{\prime}=u-\bar{u}
$$

$$
\tau_{x y}=-\rho \overline{u^{\prime} v^{\prime}}
$$

Onde u é velocidade pontual na direção $\mathrm{x}$ $(\mathrm{cm} / \mathrm{s}), \quad \bar{u}$ é velocidade média pontual considerando a tomada de 100 valores na direção $\mathrm{x}$ $(\mathrm{cm} / \mathrm{s}), \quad \rho$ é a densidade específica da água $\left(\mathrm{Kg} / \mathrm{cm}^{3}\right)$, u' é a flutuação da velocidade $(\mathrm{cm} / \mathrm{s})$ na direção x e v' é a flutuação da velocidade $(\mathrm{cm} / \mathrm{s})$ na direção y.

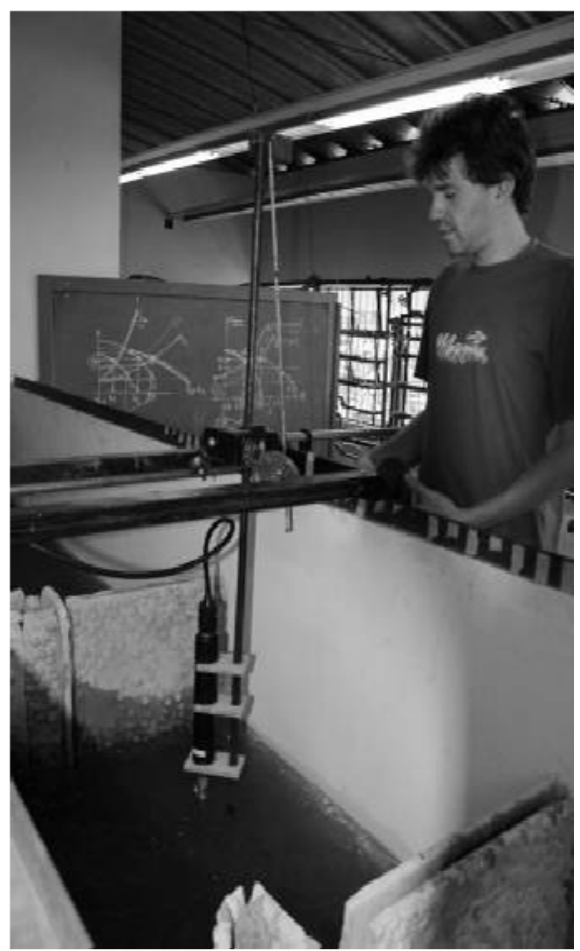

Figura 4 - Esquema de colocação do ADV. Fonte própria.

\section{Testes com o Pimelodus maculatus (mandi-amarelo)}

Para este estudo foi escolhida a espécie de peixe Pimelodus maculatus, conhecida popularmente como mandi-amarelo, cujo gênero se encontra amplamente difundido nas principais bacias da América Latina (REIS et al.,2003). Esta espécie se caracteriza por ser bentopelágica e ter hábitos noturnos (FISHBASE, 2012). Existem dúvidas quanto à necessidade de migração desta espécie para fins de reprodução (SANTOS et al., 2007). Devido sua abundância nas bacias do Prata e do São Francisco, esta espécie possui grande importância comercial (WELCOMME, 1985) e é facilmente encontrada em vários mecanismos de transposição no Brasil (FERNANDEZ et al., 2004; VONO et al., 2004; BIZZOTO, 2006).

Todos os indivíduos para os testes foram coletados no Rio São Francisco na cidade de Três Marias e permaneciam em observação por 24 horas antes de serem testados. Após os testes, os peixes eram devolvidos para os aquários e permaneciam até sua soltura em Três Marias. Todos os testes eram conduzidos em um prazo inferior a uma semana, contada a partir da coleta em campo.

Dois indivíduos eram colocados por teste no canal hidráulico e permaneciam por 10 minutos se adaptando ao escoamento. Para que não ocorresse entrada dos peixes nas tubulações do sistema, foram colocadas telas a montante e a jusante do canal. Após a adaptação era realizada a filmagem do teste.

O comprimento total dos peixes variou entre 20 e $30 \mathrm{~cm}$ e o peso de 85 a 250 gramas. Estes valores se encontram próximos dos valores conhecidos para indivíduos com tamanho de primeira maturação.

Foram testadas duas vazões: 15 e $20 \mathrm{~L} / \mathrm{s}$. O fundo do canal foi pintado, sendo o mesmo dividido em quadrados de $10 \times 10 \mathrm{~cm}$ para fins de localização dos peixes durante as filmagens.

De forma a evitar que a presença dos observadores influenciasse no comportamento dos peixes, os testes foram filmados com duas câmeras, posicionada sobre os tanques utilizados para testes com peixes (2 e 3 ). Os testes foram realizados no período da noite (a partir das 19:00) e a duração dos testes foi de 2 horas cada. Utilizou-se iluminação fluorescente tubular de cor vermelha para filmagem, sendo que o canal só recebia iluminação pela parte superior do mesmo. Após cada teste, os peixes eram pesados e medidos. Foram feitos 8 testes por vazão.

Cada teste indicou a posição mais freqüentada por um peixe, denominada moda. Essas modas foram marcadas nos gráficos, gerados através do Matlab, para ambos os tanques.

Para análise de preferência, os tanques foram divididos em: área de escoamento (AE) com 46 posições, área sob influência da parede Lisa (PL) com 32 posições e área sob influência da parede Rugosa (PR) com 21 posições. Considerando a disponibilidade de áreas, ou seja, uma vez que área do escoamento é maior que a área de influência da 
parede rugosa e do que a área de influência da parede lisa, calculou-se a preferência proporcional. Esta foi o número total de quadrantes de localização da moda dividido pelo número de quadrantes disponível em um determinado tipo de área (FIG. $5)$.

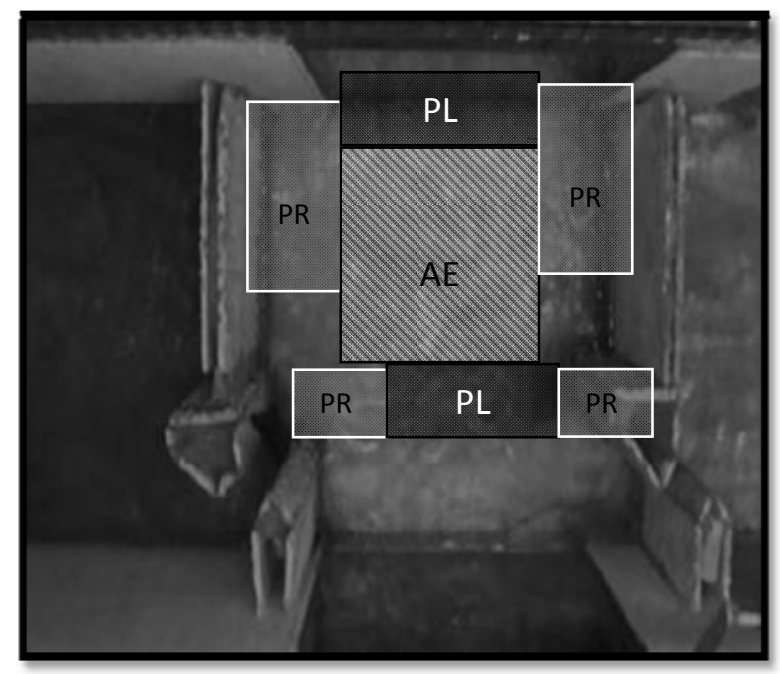

Figura 5- Divisão das areas entre as ranhuras de acordo com possível influência( $P L$ - parede lisa, $\mathbf{P R}$ - parede rugosa e $\mathrm{AE}$ - área do escoamento).

\section{RESULTADOS}

Os testes hidráulicos permitiram a obtenção de campos de velocidade para diferentes vazões (FIG. 3 e 4)e utilizou-se os dados obtidos para profundidade de $10 \mathrm{~cm}$ (a mais utilizadas pelo mandi durante ensaios prévios). Os pontos dos tanques, mais utilizados pelos peixes e obtidos através da moda, foram mais próximos das paredes na vazão de $15 \mathrm{~L} / \mathrm{s}$ do que para a vazão de $20 \mathrm{~L} / \mathrm{s}$.

Considerando a velocidade para os planos referenciais a superfície da água, para vazão de 15 $\mathrm{L} / \mathrm{s}$, os pontos mais freqüentados tinham velocidade entre 0 e $30 \mathrm{~cm} / \mathrm{s}$ (FIG. 6). Já para a vazão de 20 $\mathrm{L} / \mathrm{s}$ alguns destes pontos apresentaram velocidades acima de $60 \mathrm{~cm} / \mathrm{s}$ (FIG. 7).

Considerando a tensão turbulenta no plano xy, os pontos mais freqüentados apresentaram valores positivos de até $10 \mathrm{~Pa}$. Isto ocorreu tanto para vazão de $15 \mathrm{~L} / \mathrm{s}$ como para vazão $20 \mathrm{~L} / \mathrm{s}$ (FIG. 8 e 9$)$.
Com relação à flutuação (FIG. 10 e 11), verifica-se que para as duas vazões, o modelo ranhura vertical apresenta variações em valores positivos e negativos em todos os tanques. No escoamento principal ocorrem os valores extremos (acima de $200 * 10^{-16} \mathrm{~cm} / \mathrm{s}$ ou abaixo de $-200 * 10^{-16}$ $\mathrm{cm} / \mathrm{s})$. As posições mais freqüentadas pelos peixes possuíram valores próximos a $0 * 10^{-16} \mathrm{~cm} / \mathrm{s}$. Ressaltase que os baixos valores são reflexos da obtenção da flutuação por meio de cálculos matemáticos com as variáveis medidas (u' e v').

A flutuação na direção "x" não apresentou valores médios e máximos diferentes entre as vazões (TAB. 1). Entretanto, diferenças foram observadas para os valores médios e máximos de velocidade e tensão turbulenta em xy.

Os pontos no escoamento localizados próximos às paredes rugosas (distância de $5 \mathrm{~cm}$ ), apresentam maiores variações médias do que os pontos localizados próximos às paredes lisas (distância de $5 \mathrm{~cm}$ ) considerando os parâmetros velocidade, tensão turbulenta e flutuação (Fig. 12). Os valores de mínimos e máximos também foram mais extremos para paredes rugosas.

TABELA 1 - Valores médios e máximos considerando todos os pontos medidos nos três tanques

\begin{tabular}{|l|c|c|c|}
\hline & & $\mathbf{1 5 L} / \mathbf{s}$ & $\mathbf{2 0 L} / \mathbf{s}$ \\
\hline $\begin{array}{l}\text { Velocidade } \\
(\mathbf{c m} / \mathbf{s})\end{array}$ & Média & 23.7 & 27.2 \\
\cline { 2 - 4 } & Máxima & 99.1 & 109.7 \\
\hline $\begin{array}{l}\text { Flutuação } \\
\left(\mathbf{1 0}^{-16} \mathbf{c m} / \mathbf{s}\right)\end{array}$ & Média & $3.96 \mathrm{E}-15$ & $3.96 \mathrm{E}-15$ \\
\cline { 2 - 4 } & Máxima & $5.00 \mathrm{E}-14$ & $5.53 \mathrm{E}-14$ \\
\hline $\begin{array}{l}\text { Tensão Turbu- } \\
\text { lenta }(\mathbf{P a})\end{array}$ & Média & 2.6 & 4.0 \\
\cline { 2 - 4 } & Máxima & 34.7 & 96.4 \\
\hline
\end{tabular}

Dividindo os tanques em área do escoamento, área de influência da parede rugosa e área de influência de parede lisa; e considerando a preferência proporcional, verificou-se que para vazão de $15 \mathrm{~L} / \mathrm{s}$ áreas influenciadas pela parede rugosa apresentaram grande preferência nos dois tanques (FIG. 13).

O mesmo não ocorreu para a vazão de 20 L/s (FIG. 14). Entretanto, para esta vazão foi possível observar que ainda assim os peixes preferiram paredes, neste caso as lisas. 


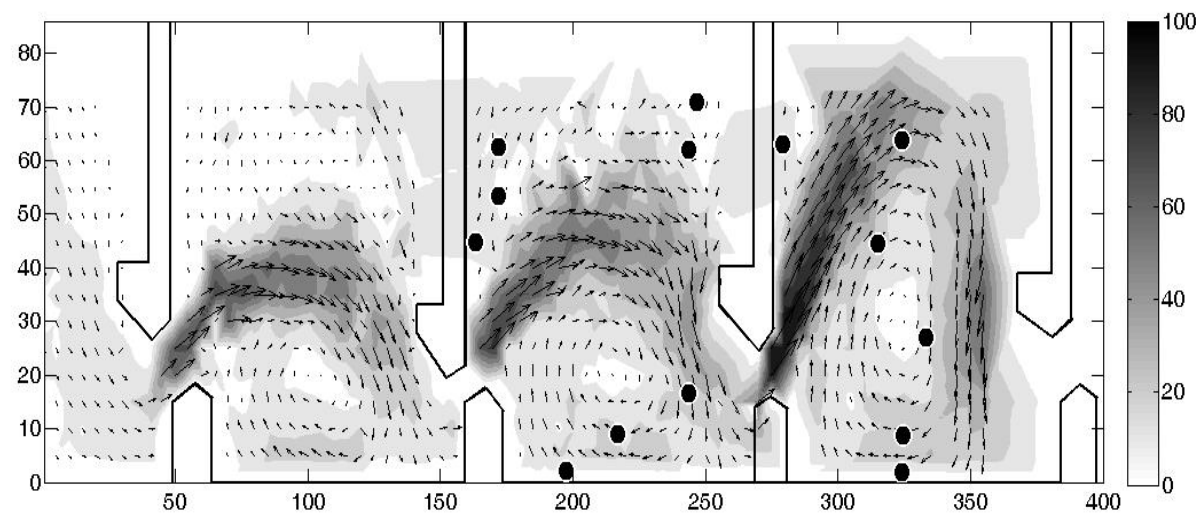

Figura 6 - Velocidade em cm/s para vazão de $15 \mathrm{~L} / \mathrm{s}$ na profundidade de $10 \mathrm{~cm}$. Pontos pretos representam a moda da posição de um peixe em um ensaio.

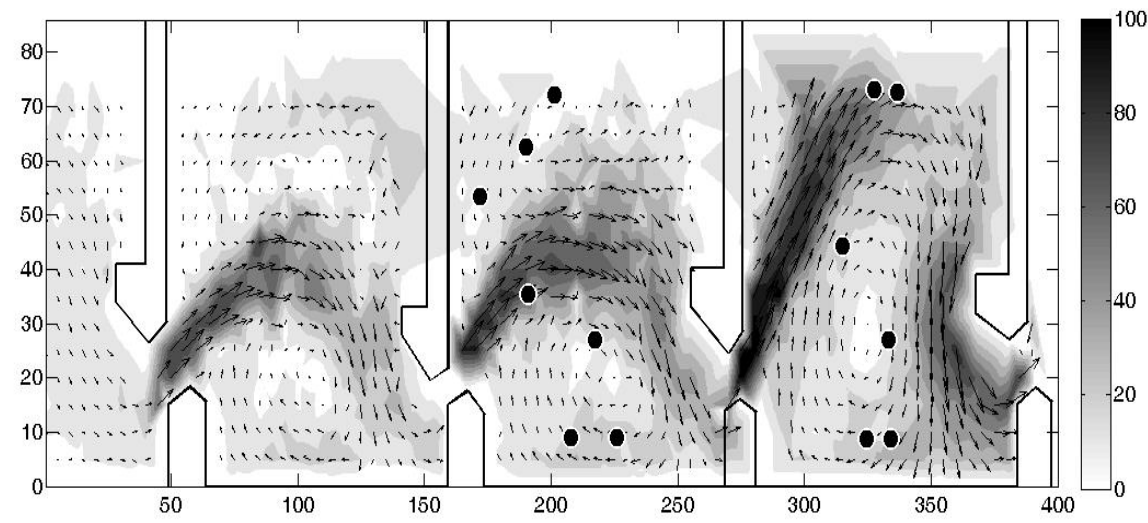

Figura 7 - Velocidade em $\mathrm{cm} / \mathrm{s}$ para vazão de $20 \mathrm{~L} / \mathrm{s}$ na profundidade de $10 \mathrm{~cm}$. Pontos pretos representam a moda da posição de um peixe em um ensaio.

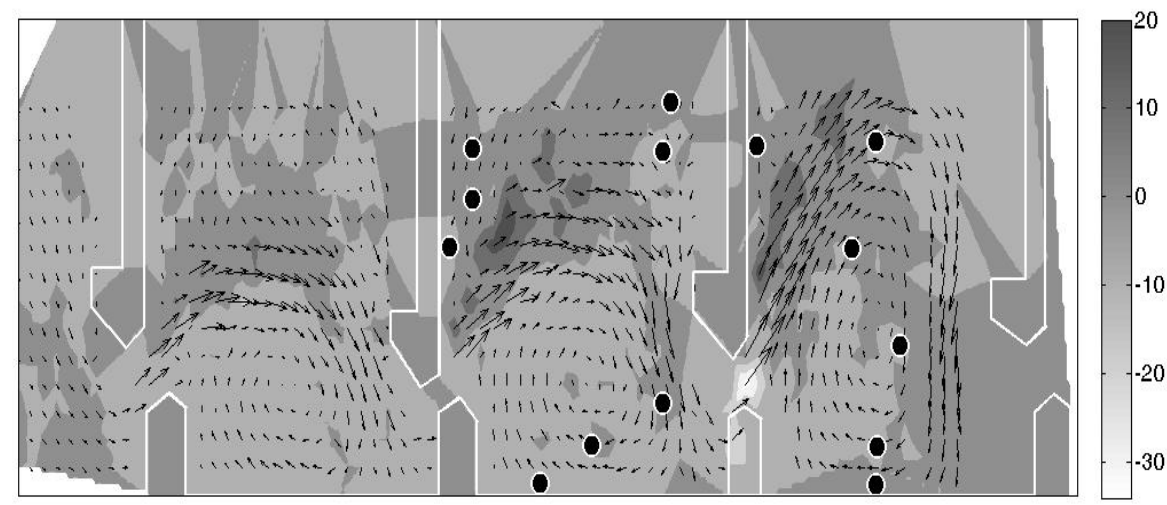

Figura 8 - Tensão turbulenta no plano xy em Pa para vazão de $15 \mathrm{~L} / \mathrm{s}$ na profundidade de $10 \mathrm{~cm}$. Pontos pretos representam a moda da posição de um peixe em um ensaio (na piscina 1 mais de um moda ocorreram no mesmo local) 


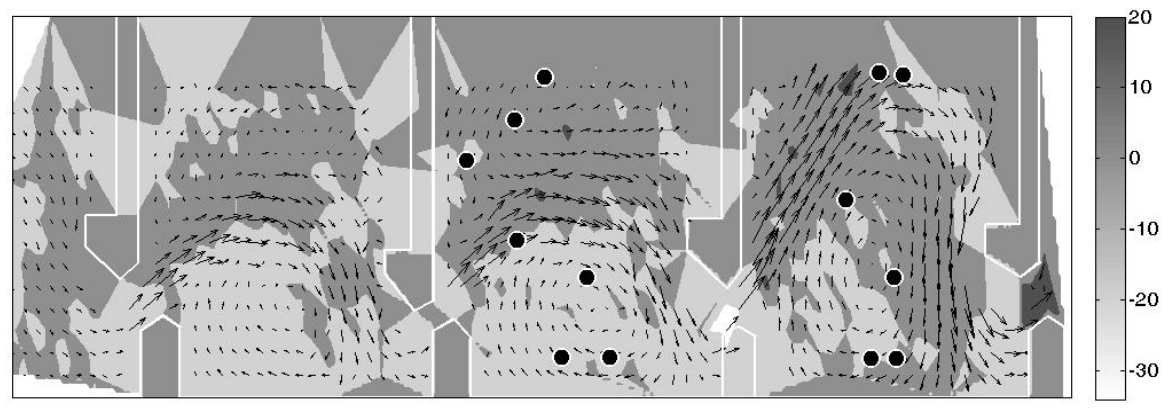

Figura 9 - Tensão turbulenta no plano xy em Pa para vazão de $20 \mathrm{~L} / \mathrm{s}$ na profundidade de $10 \mathrm{~cm}$. Pontos pretos representam a moda da posição de um peixe em um ensaio (na piscina 1 mais de um moda ocorreram no mesmo local).

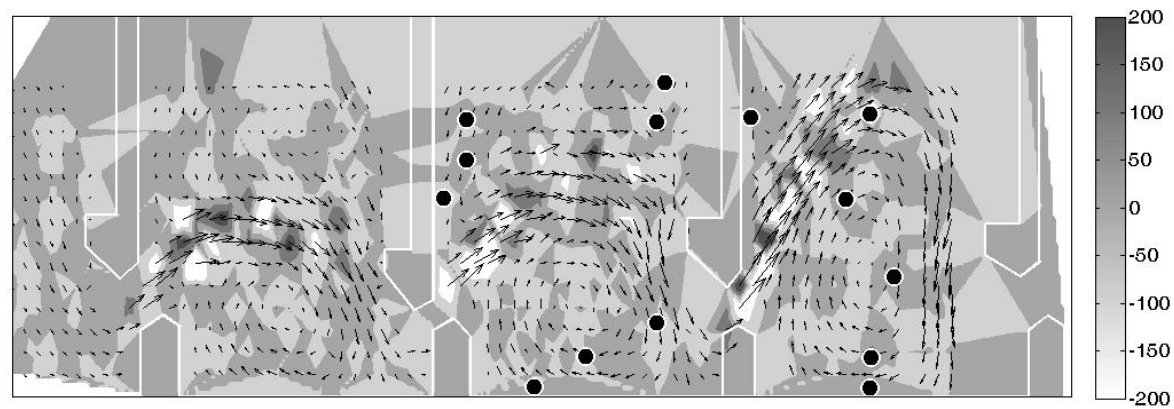

Figura 10 - Flutuações da velocidade na direção $\times \mathrm{em} \mathrm{cm} / \mathrm{s}$ x 10-16 para vazão de $15 \mathrm{~L} / \mathrm{s}$ na profundidade de $10 \mathrm{~cm}$. Pontos pretos representam a moda da posição de um peixe em um ensaio (na piscina 1 mais de um moda ocorreram no mesmo local).

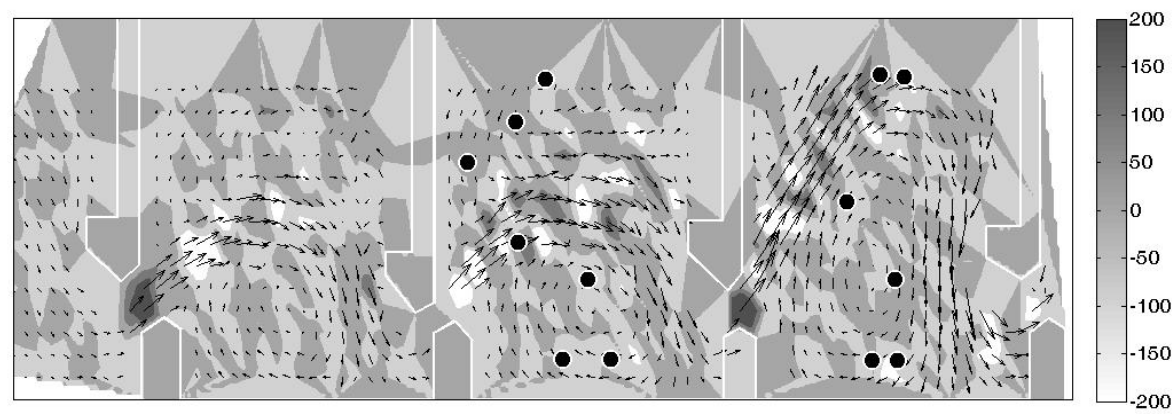

Figura 11 - Flutuações da velocidade na direção $\mathrm{em} \mathrm{cm} / \mathrm{s} \times 10-16$ para vazão de 20L/s na profundidade de $10 \mathrm{~cm}$. Pontos pretos representam a moda da posição de um peixe em um ensaio (na piscina 1 mais de um moda ocorreram no mesmo local).

\section{DISCUSSÃO}

A escada ranhura vertical se caracteriza por apresentar níveis de dissipação de energia diferente entre as ranhuras quando o escoamento interno é gradualmente variado (RAJARATNAM et al. 1986). Este padrão pode ser observado ao longo dos três tanques estudados, de forma que o tanque 3, localizado mais a jusante do trecho de estudo, apresentou os maiores valores de flutuação, tensão turbulenta e velocidade. Desta forma, quando 
posicionados no tanque 3 , os mandis tiveram que experimentar velocidade superiores (da ordem de $60 \mathrm{~cm} / \mathrm{s})$.

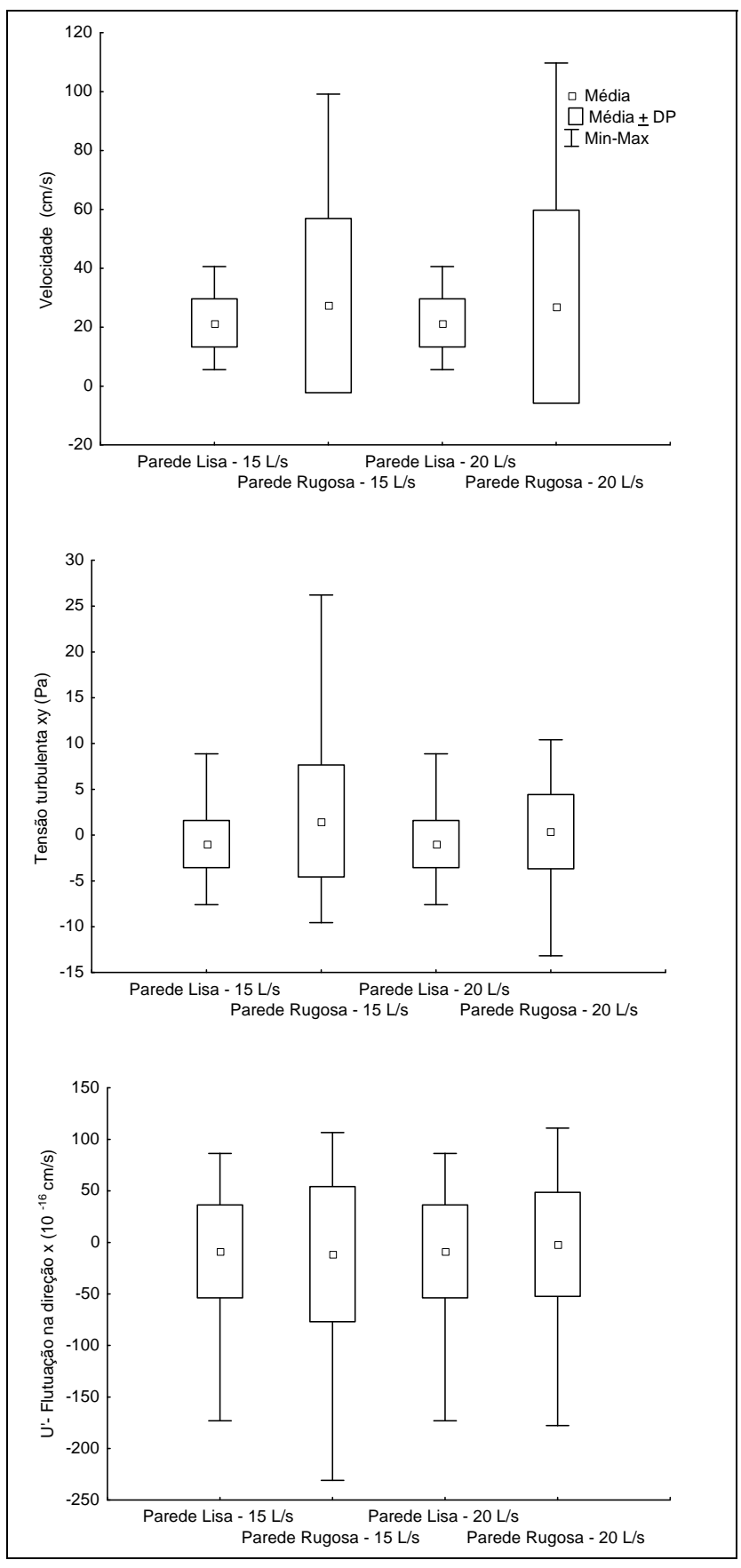

Figura 12 - a) Velocidade pontual b) Tensão turbulenta xy c)Flutuação para pontos localizados à $5 \mathrm{~cm}$ das respectivas paredes.

O mandi amarelo, buscou no presente estudo, as áreas próximas às paredes. Quando o escoamento apresentou valores mais baixos de tensão cisalhante e velocidade, o que ocorreu na vazão de $15 \mathrm{~L} / \mathrm{s}$, os indivíduos testados tiveram preferência pelas paredes rugosas. A velocidade (RODRÍGUEZ et al., 2006) e a tensão cisalhante (SILVA et al.,2010) têm-se apresentado importantes parâmetros no projeto de mecanismos de transposição otimizados para espécies encontrada na Europa.

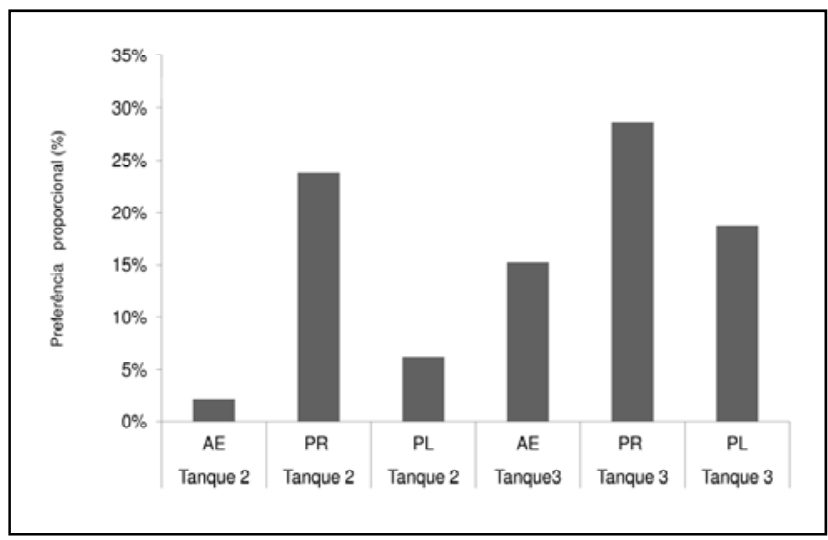

Figura 13 - Analise de preferência proporcional para vazão de $15 \mathrm{~L} / \mathrm{s}$.

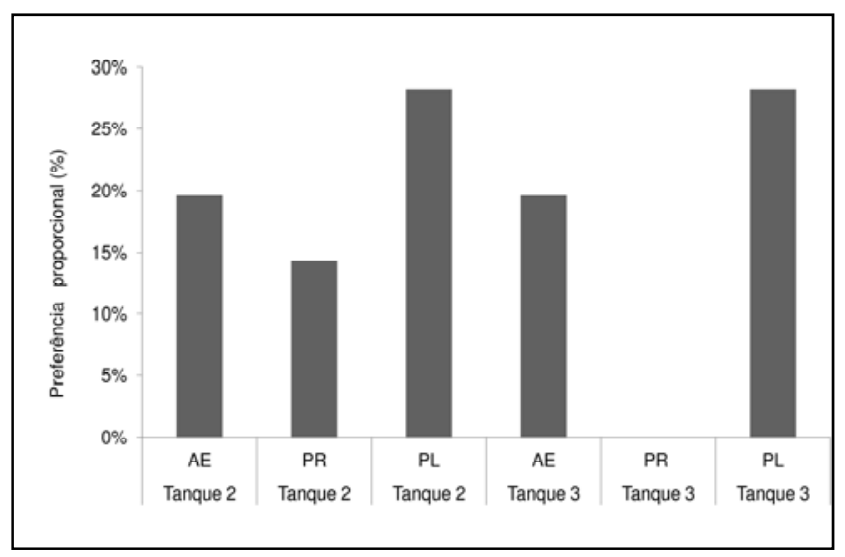

Figura 14 - Analise de preferência no tanque 3 com vazão de $20 \mathrm{~L} / \mathrm{s}$.

Quando localizados na área do escoamento principal, os peixes evitaram o centro do grande vórtice formado nos tanques. $\mathrm{O}$ padrão de negociação de passagem na escada ranhura vertical foi identificado como o de posicionamento próximo a ranhura vertical (a jusante da ranhura) e a parede lateral direita (considerando a direção principal como a do escoamento). Este padrão também já foi verificado para algumas espécies de peixes de clima temperado (WANG et al., 2010). 
As variações dos parâmetros hidráulicos próximos às paredes rugosas são capazes de ser percebidas pelos mandis quando ocorrem no escoamento principal tensões cisalhantes mais baixas (neste caso de ordem média de 2,6 Pa e de ordem máxima de $35 \mathrm{~Pa}$ ).

Desta forma, áreas próximas à paredes rugosas podem atrair a espécie Pimelodus maculatus em determinadas condições, sendo este um fator a ser considerado no projeto de escadas eficientes. Entretanto, métodos para instigar a passagem de cardumes devem ser também avaliados, de forma a evitar a permanência demasiada dos peixes no mecanismo de transposição.

\section{AGRADECIMENTOS}

Os autores são gratos à FAPEMIG pelo apoio financeiro a esta pesquisa e as funcionários Wenceslau e Itamar do Laboratório de Hidráulica do CEFET-MG pelo auxílio operacional aos experimentos.

\section{REFERÊNCIAS}

Agostinho, A. A.; GOMES, L. C., FERNANDEZ, D. R. e SUZUKI, H. I.. Efficiency of fish ladders for Neotropical ichthyofauna. River Research and Applications. v. 18, p: 299306, 2002

BALDIGO, B. P.; WARREN, D. R.; ERNST, A. G. E MULVIHILL, C. I..Response of Fish Populations to Natural Channel Design Restoration in Streams of the Catskill Mountains, New York, North American Journal of Fisheries Management. v. 28 (3), p: 954-969

BIZOTTO, P. M., Trânsito de peixes na escada da UHEIgarapava, Rio Grande, Alto Paraná. Dissertação de Mestrado em Zoologia de Vertebrados, PUC Minas, Belo Horizonte, p. 52,2006

FISHBASE, 2012. Disponível em: <http://www.fishbase.org/>. Acessado em agosto de 2012.

FERNANDEZ, D. R.; AGOSTINHO, A. A. e BINI, L. M. Selection of an experimental fish ladder located at the dam of the Itaipu Binacional, Paraná river, Brazil. Brazilian Archives of Biology and Technology, v. 47, n. 4, p: 579-586, 2004
JUNHO, R. A. C. Migrações ascendentes de peixes neotropicais e hidrelétricas: Proteção a jusante de turbinas e vertedouros e sistemas de transposição. Tese (doutorado) em Engenharia, Escola Politécnica, Universidade de São Paulo, São Paulo, 2008.

KATOPODIS, C. Introduction to Fishway Design. Winnipeg: Freshwater Institute, 67p., 1992.

KUAMAL, C M. e FERREIRAL, F. W. Mecanismo de transposição de peixes de pequena central hidrelétrica. Revista Ciência Rural, 2009

LARINIER, M. Fishways- General considerations. In: LARINIER M.; TRAVADE F.; PORCHER J. P., 2002, Fishways: biological basis, design criteria and monitoring. Bulletin Fr. Pêche Piscic., n. 364, cap 2, p: 21-27, 2002.

MAKRAKIS, S.; GOMES, L. C.; MAKRAKIS, M. C.; FERNANDEZ, D. R. e PAVANELLI, C. S. The Canal da Piracema at Itaipu Dam as a fish pass system. Sociedade Brasileira de Ictiologia. Neotropical Ichthyology. v. 5, n.2, p:185-195, 2007.

MARTINS, S. L. Sistemas para a Transposição de Peixes Neotropicais Potamódromos. Tese (doutorado) em Engenharia, Escola Politécnica, Universidade de São Paulo, São Paulo, 2005.

MEHTA, P. K. e MONTEIRO, P. J. M. Concreto: Estrutura, Propriedades e Materiais. 1.ed. São Paulo: PINI, 581p, 2005

PELICICE, F. M. e AGOSTINHO, A. A. Fish-Passage Facilities as Ecological Traps in Large Neotropical Rivers.Conservation Biology. v. 22. n.1. p: 180-188, 2008.

POMPEU, P. S. e MARTINEZ, C. B. Efficiency and selectivity of a trap and truck fish passage system in Brazil. Sociedade Brasileira de Ictiologia. Neotropical Ichthyology. v.5, n.2, p: 169-176, 2007.

RAJARATNAM, N., VAN DER VINNE, G. e KATOPODIS, C. Hydraulics of vertical slot fishways. Journal of Hydraulic Engineering, v. 112, p: 909-927, 1986

REIS, R. E.; KULLANDER, S.O. e FERRARIS Jr., C.J. Check list $f$ the freshwater fishes of South and Central America. Porto Alegre: EDIPUCRS. 742p., 2003.

RODRÍGUEZ, T. T.; AGUDO, J. P.; MOSQUERA, L. P. e GONZÁLEZ, E. P. Evaluating vertical-slot fishway designs in terms of fish swimming capabilities, Ecological Engineering, v. 27, p: 37:48, 2006 
SANTOS, H. A.; POMPEU, P. S. e MARTINEZ, C. B. Swimming performance of the migratory Neotropical fish Leporinus reinhardti (Characiformes: Anostomidae) Neotropical Ichthyology, v.5, n. 2, p: 139-146, 2007.

SANTOS, H. A.; POMPEU, P. S. e MARTINEZ, C. B. Estabelecimento de parâmetros hidráulicos para escadas de peixes do tipo ranhura vertical, baseados em características de espécies neotropicais. Revista Brasileira de Recursos Hídricos, v. 14, p: 99-112, 2009.

SILVA, A. T.; FERREIRA, M. T.; PINHEIRO, A. N.; KATOPODIS, C. Effects of water velocity and turbulence on the behaviour of Iberian barbel (Luciobarbus bocagei, Steindachner 1864) in an experimental pool-type fishway. River Research and Applications, 2010.

VIANA, E. M. F.; FARIA, M. T.C. e MARTINEZ, C B. Levantamento das Curvas do Comportamento Hidráulico do Mecanismo de Transposição de Peixes da UHE de Igarapava. Revista: RBRH - Revista Brasileira de Recursos Hídricos. v. 14. n.1. p: 113-122 2009.

VONO, V.; BIZZOTTO, P. M.; GODINHO, H. P.; GODINHO, A. L. e KYNARD, B. Fish passage at the Igarapava Fish Ladder, River Grande, Brazil. In International Congress on the Biology of Fish Tropical Hotel Resort, Manaus Brazil. 5p. 2004

WANG, R.W.; DAVID L. e LARINIER M. Contribution of experimental fluid mechanics to the design of vertical slot fish passes. Knowledge and Management of Aquatic Ecosystems, v. 396, n.02, 2010

WELCOMME, R. L., River fisheries. FAO Fish. Tech. Pap., n. 262, 330p. 1985

\section{Addition Of Roughness To The Concrete Of Fish Ladders: Analysis For The Neotropical Species Pimelodus Maculatus}

\section{ABSTRACT}

Brazilian hydropower generation is one of the largest worldwide. Consequently, several conditions should be analyzed before dam construction. This includes, especially, environmental implications such as the impact on the migratory routes of some fish species, whose reproduction sites are located upstream from the dam. In order to mitigate this problem, fishways were developed. The laddertype vertical slot is the most applied in Brazil and is usually made of smooth concrete, which produces a completely different environment from the natural course of rivers.
Therefore this study aims to evaluate the effect of increased roughness in the slots of a ladder on the hydraulic flow, considering also the influence on fish behavior. For this study we have built a scale model and we have done fish tests at night. The results show that there is a preference of the species for roughness in discharges with maximum turbulent shear in xy of $35 \mathrm{~Pa}$. The punctual velocity and turbulent shear in xy show the highest variation for roughness changes.

Key-words: ladder-type vertical slot, roughness and Pimelodus maculatus 